\title{
Blood pressure, frailty status, and all-cause mortality in elderly hypertensives; The Nambu Cohort Study
}

\author{
Taku Inoue ${ }^{1,2} \cdot$ Mitsuteru Matsuoka $^{3} \cdot$ Tetsuji Shinjo $^{1} \cdot$ Masahiro Tamashiro $^{4} \cdot$ Kageyuki Oba $^{4} \cdot$ Masanori Kakazu $^{4}$. \\ Takuhiro Moromizato ${ }^{5}$ Osamu Arasaki ${ }^{4}$ Hisatomi Arima ${ }^{2}$
}

Received: 21 July 2021 / Revised: 14 September 2021 / Accepted: 15 September 2021 / Published online: 15 October 2021

(c) The Author(s) 2021. This article is published with open access

\begin{abstract}
Antihypertensive therapy is pivotal for reducing cardiovascular events. The 2019 Guidelines for the Management of Hypertension set a target blood pressure (BP) of $<140 / 90 \mathrm{mmHg}$ for persons older than 75 years of age. Optimal BP levels for older persons with frailty, however, are controversial because evidence for the relationship between BP level and prognosis by frailty status is limited. Here, we evaluated the relationship between systolic BP and frailty status with all-cause mortality in ambulatory older hypertensive patients using data from the Nambu Cohort study. A total of 535 patients (age 78 [70-84] years, 51\% men, 37\% with frailty) were prospectively followed for a mean duration of 41 (34-43) months. During the follow-up period, 49 patients died. Mortality rates stratified by systolic BP and frailty status were lowest in patients with systolic $\mathrm{BP}<140 \mathrm{mmHg}$ and non-frailty, followed by those with systolic $\mathrm{BP} \geq 140 \mathrm{mmHg}$ and non-frailty. Patients with frailty had the highest mortality regardless of the BP level. The adjusted hazard ratios (95\% confidence intervals) of each category for all-cause mortality were as follows: $\geq 140 \mathrm{mmHg} / \mathrm{Non}$-frailty $3.19(1.12-11.40),<140 \mathrm{mmHg} / \mathrm{Frailty} 4.72$ (1.67-16.90), and $\geq 140 \mathrm{mmHg} /$ Frailty 3.56 (1.16-13.40) compared with $<140 \mathrm{mmHg} / \mathrm{Non}$-frailty as a reference. These results indicated that frail patients have a poor prognosis regardless of their BP levels. Non-frail patients, however, with systolic BP levels $<140 \mathrm{mmHg}$ had a better prognosis. Frailty may be a marker to differentiate patients who are likely to gain benefit from antihypertensive medication among older hypertensives.
\end{abstract}

Keywords Frailty $\cdot$ Blood pressure $\cdot$ Mortality

\section{Introduction}

Hypertension is a significant risk factor for cerebrovascular disease [1-3], and antihypertensive therapy can reduce the onset, progression, and recurrence of cerebrovascular disease leading to the risk of deterioration of quality of life or

Taku Inoue

imtak-ryk@umin.ac.jp

1 Cardiovascular Medicine, Tomishiro Central Hospital, Tomigusuku, Japan

2 Department of Preventive Medicine and Public Health, Faculty of Medicine, Fukuoka University, Fukuoka, Japan

3 Matsuoka Clinic, Tomigusuku, Japan

4 Cardiovascular Medicine, Yuai Medical Center, Tomigusuku, Japan

5 Renal and Rheumatorogy Division, Nanbu Medical Center and Children's Medical Center, Haebaru, Japan death [4-6]. There is a log-linear association between blood pressure (BP) levels and cardiovascular mortality hazard ratios (HRs), but the slope is smaller in older individuals, and the contribution of BP to the development of cerebrovascular events is lower [1,7]. When this study started in 2017, elderly hypertensive patients were managed according to 2014 Japanese Society of Hypertension Guidelines for the Management of Hypertension (JSH 2014) [8], which recommended BP control of $<140 / 90$ for those aged $65-74$ years and $<150 / 90 \mathrm{mmHg}$ for those aged 75 years and older. Based on the results of randomized control trials of antihypertensive treatment for the elderly, the 2019 Japanese Society of Hypertension Guidelines for the Management of Hypertension (JSH 2019) set the target BP value for antihypertensive therapy in persons 75 years of age or older as $<140 / 90 \mathrm{mmHg}$ [9]. Frailty should be considered as a factor in the debate on optimal BP levels for older hypertensive patients. Frailty is a state of increased vulnerability resulting from an age-associated decline in reserve and function over multiple physiologic systems such that the ability to cope with everyday or acute stressors is compromised [10]. 
Fig. 1 Diagram of the study

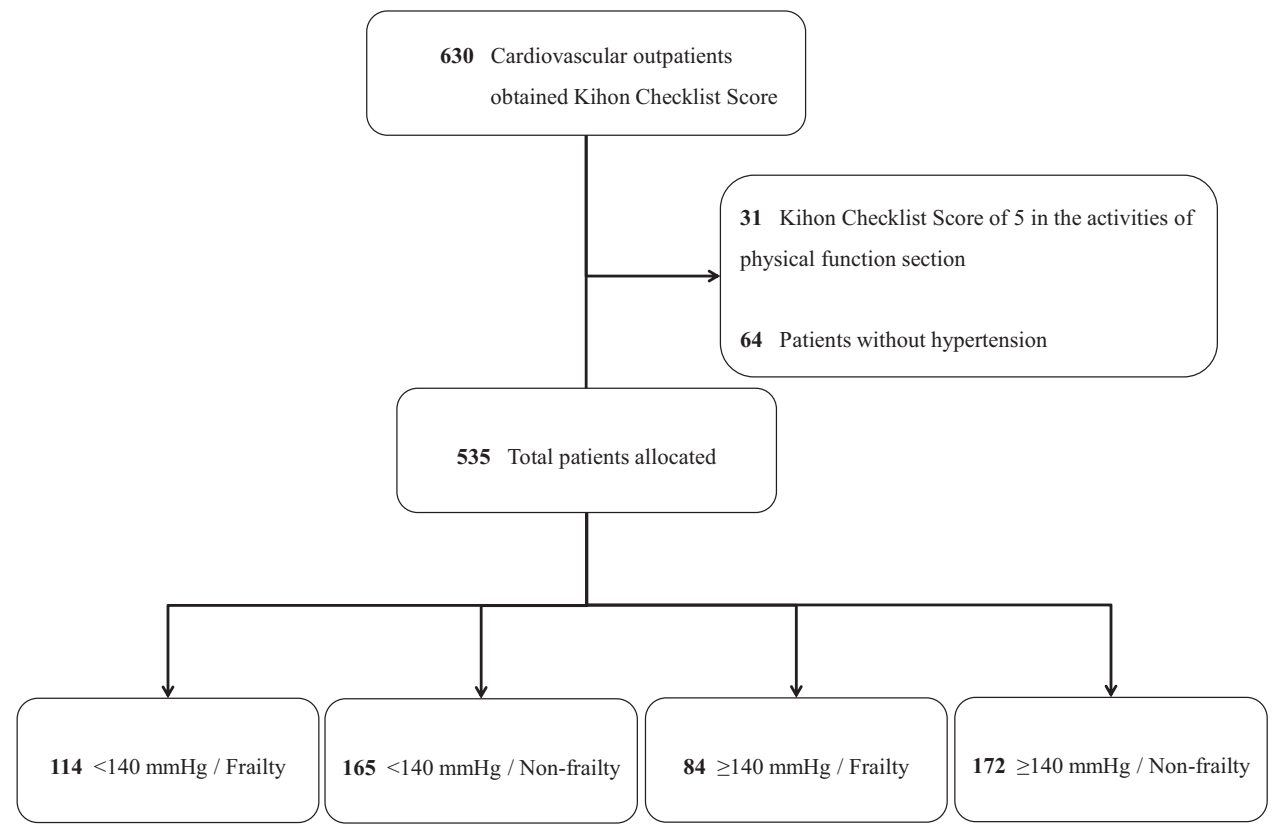

Although frailty is associated with impaired activities of daily living due to deterioration in physical function, the biggest problem with frailty is increased hospitalization and worsening life expectancy [11]. Furthermore, while patients with frailty have a higher prevalence of comorbidities [12], cardiovascular risk levels are somewhat lower [12-14], and lower BP levels in frailty are associated with poor prognosis [15]. Due to the limited evidence available on antihypertensive therapy in patients with frailty $[16,17]$, coupled with the absence of clear diagnostic criteria for frailty [17], there is no consensus on the optimal BP level for hypertensive patients with frailty, which currently relies on the clinician's experience. In this background, we examined how frailty status affects initial BP levels and subsequent mortality rate in older hypertensive patients using data from the Nambu Cohort Study, a prospective observational study of older outpatients.

\section{Methods}

\section{Study patients and data collection}

The Nambu Cohort Study is a prospective cohort study of older patients in an outpatient setting in the southern area of Okinawa, Japan, that began in 2017 [13]. We collect and accumulate data on the anthropometric indices, comorbidities, cardiovascular risk profiles, blood test data, prescribed drugs, and physical function of outpatients aged 65 years or over. Our ultimate goal is to provide evidence for factors contributing not only to a patients' disease prognosis, but also those contributing to a better healthy life expectancy.
Patients who could complete the interview conducted by the medical assistant to provide information regarding frailty were continuously registered. Among the original registry, those with a Kihon Checklist (KCL) score of 5 (the worst) in the physical function section, and those without diagnosed hypertension were excluded. Finally, 535 patients were allocated to four categories according to their initial $\mathrm{BP}$ and frailty status as follows; $<140 \mathrm{mmHg} /$ Frailty $(n=$ $114), \quad<140 \mathrm{mmHg} / \mathrm{Non}$-frailty $(n=165), \quad \geq 140 \mathrm{mmHg} /$ Frailty $(n=84)$, and $\geq 140 \mathrm{mmHg} / \mathrm{Non}$-frailty $(n=172)$ (Fig. 1).

\section{Definition of clinical disease}

A trained nurse measured the patient's height and body weight before the outpatient examination. Body weight and height were measured with the patient in indoor clothing without shoes. Body mass index was calculated as the weight in kilograms divided by the square of the height in meters $\left(\mathrm{kg} / \mathrm{m}^{2}\right)$. Blood pressure (BP) was measured once in the sitting using an automatic BP monitor (HBP-9020, Omron Corp., Kyoto, Japan) after resting for about $10 \mathrm{~min}$ on either the left or right upper arm. All blood samples were obtained from the antecubital vein after overnight fasting. Enzymatic methods were used to measure serum creatinine, total cholesterol, triglycerides, and low-density lipoprotein cholesterol levels, and the direct method was used to measure high-density lipoprotein cholesterol. The hexokinase/ glucose-6-phosphate dehydrogenase method was used to measure fasting plasma glucose. High-performance liquid chromatography was used to measure the hemoglobin A1c level. Blood cell measurements such as leukocyte count, 
hematocrit, hemoglobin level, and platelet count were quantified using an automated blood cell counter. A Smedley-type (mechanical) hand grip dynamometer (TTM, Tokyo, Japan) was used to measure grip strength.

In this study, the KCL was used to diagnose frailty. The KCL was developed by the Japanese Ministry of Health, Labor and Welfare to identify elderly individuals at risk of requiring care/support [18]. The KCL is a simple selfreporting yes/no survey comprising 25 questions regarding instrumental and social activities of daily living, physical functions, nutritional status, oral function, cognitive function, and depressive mood. Satake et al. verified the clinical usefulness of the KCL as a frailty indicator [19]. Patients with a KCL Score of 0-3 were diagnosed as robust, 4-7 with prefrailty, and 8 or over with frailty [19]. Well-trained medical staff asked the patients about the content of the KCL before the medical examination and recorded the patients' responses.

\section{Statistical analysis and ethics}

Continuous variables are expressed as median (interquartile range) and categorical variables as percentages. The median values of continuous variables were compared using the Kruskal-Wallis test. Categorical variables were compared using the chi-square test. The Kolmogorov-Smirnov test was used to evaluate the distribution normality. The mortality rate was calculated as the total number of outcomes during the follow-up period divided by 100 patient-years. For statistical analysis, the patients were stratified into two groups according to their frailty status, with robust and prefrail being considered non-frail. A multivariate analysis was performed using the Cox proportional hazard model to evaluate the relationship of BP and frailty status with allcause mortality. Hazard ratios (HRs) and 95\% confidence intervals (CIs) were calculated and adjusted for age, sex, diabetes, dyslipidemia, obesity, chronic kidney disease, stroke, coronary artery disease, heart failure, and antihypertensive drug use such as calcium channel blockers and renin-angiotensin system inhibitors. Interaction between systolic BP and frailty was investigated by adding interaction terms to the statistical models. Statistical analyses performed using JMP 9.0.2 (SAS Institute Inc., Cary, NC, USA). All statistical tests were two-sided, and $p<0.05$ was considered statistically significant. The study design was approved by the local ethics committee (Social Medical Corporation Yuaikai, Okinawa, Japan H30R009) and conducted according to the Declaration of Helsinki.

\section{Results}

A total of 535 older hypertensive patients (age 78 [71-84] years, $51 \%$ men, $37 \%$ with frailty) were prospectively followed for a mean duration of 41 (34-43) months. The prevalence of robustness, pre-frailty, and frailty was $29 \%$, $34 \%$, and $37 \%$, respectively (Fig. 2). Table 1 shows the baseline characteristics of the patients stratified by systolic BP and frailty status. Within the same systolic BP category, frail patients were older with a higher prevalence of female sex, heart failure, stroke, peripheral arterial disease, and atrial fibrillation, than patients without frailty. Furthermore, patients with frailty had lower BP, body mass index, hand grip strength, estimated glomerular filtration rate, serum lipids, hemoglobin, and hematocrit levels than those without frailty, while uric acid, blood glucose, and HbA1c levels, and white blood cell count were similar (Table 2). During the median follow-up period of 41 (34-43) months, 49 patients died.

The adjusted HRs and 95\% CIs for all-cause mortality of each systolic BP and frailty status category are shown in Fig. 3. Compared with patients in the $<140 \mathrm{mmHg} / \mathrm{Non}-$ frailty category as a reference, patients with frailty had a higher HR for all-cause death regardless of their BP levels (<140 mmHg/Frailty; HR 4.72 [95\% CI 1.67-16.90], $\geq 140$ mmHg/Frailty; HR 3.56 [95\% CI 1.16-13.40]), and $\geq 140$ mmHg/Non-frailty; HR 3.19 [95\% CI 1.12-11.40]; Fig. 3). We again performed a multivariate analysis with systolic $\mathrm{BP}$ and frailty as independent covariates to assess whether systolic BP and frailty were independently associated with all-cause mortality. The results showed that frailty doubled the risk of all-cause mortality compared to non-frail (HR $2.00,95 \%$ CI $1.01-4.05, p=0.0467)$. On the other hand, systolic BP $\geq 140 \mathrm{mmHg}$ did not significantly increase the risk of all-cause mortality compared with <systolic BP140 mmHg (HR 1.17, 95\% CI 0.65-2.11, $p=0.6045$ ).

The number of all-cause deaths and mortality rates for each systolic BP level and frailty status is shown in Table 3. The mortality rate was lowest in patients with a systolic BP $<140 \mathrm{mmHg} / \mathrm{Non}$-frailty, followed by those with systolic $\mathrm{BP} \geq 140 \mathrm{mmHg} / \mathrm{Non}$-frailty. The mortality rate was higher in patients with frailty than in those without frailty. In addition, frail patients with lower systolic BP level had higher mortality rate than those with higher systolic BP level (Table 3).

Re-evaluation of those patients aged 75 years or older revealed that HRs increased and 95\% CIs varied more, but the trend was the same as for all patients (Data are not shown). The marginal significance of an interaction between systolic BP and frailty partly supports these results $(P=$ 0.085 for interaction).

\section{Discussion}

The results of the present study in which older hypertensive patients were followed in an outpatient setting demonstrated 
Fig. 2 Distribution of the Kihon Checklist score of 535 hypertensive patients in the Nambu Cohort Study
Table 1 Baseline characteristics of 535 patients in the Nambu Cohort Study stratified by blood pressure and frailty status

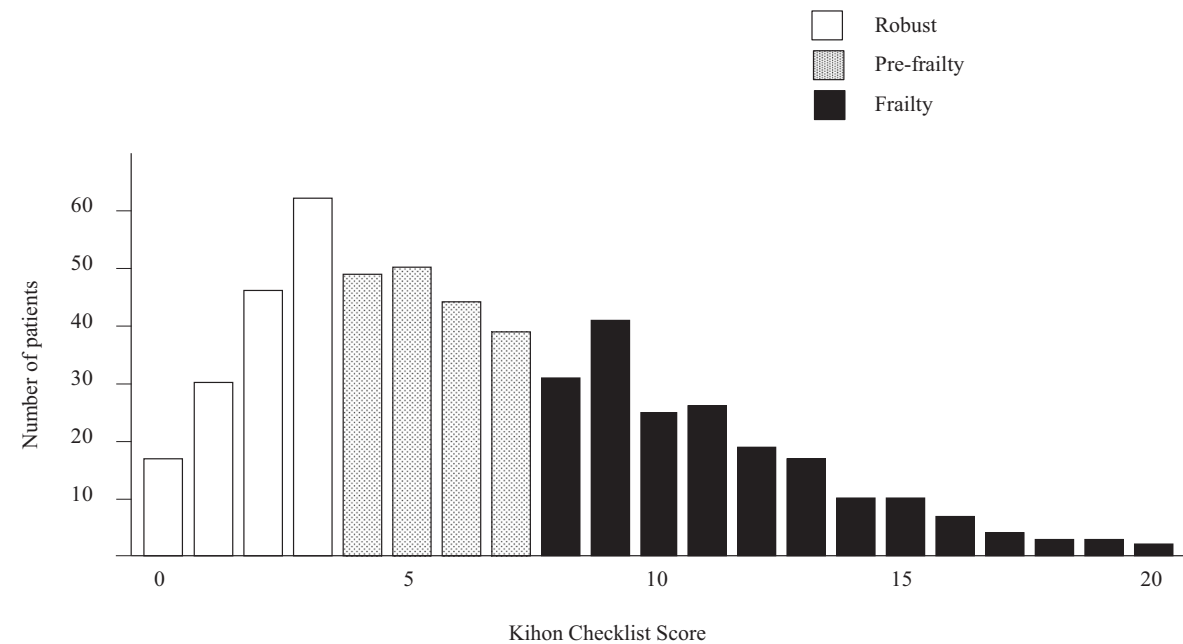

\begin{tabular}{|c|c|c|c|c|c|}
\hline & \multicolumn{2}{|l|}{$<140 \mathrm{mmHg}$} & \multicolumn{2}{|l|}{$\geq 140 \mathrm{mmHg}$} & \multirow[t]{2}{*}{$p$} \\
\hline & $\begin{array}{l}\text { Frailty } \\
n=114\end{array}$ & $\begin{array}{l}\text { Non-frailty } \\
n=165\end{array}$ & $\begin{array}{l}\text { Frailty } \\
n=84\end{array}$ & $\begin{array}{l}\text { Non-frailty } \\
n=172\end{array}$ & \\
\hline Age (years) & $82(75-87)$ & $75(69-80)$ & $84(80-89)$ & $76(68-81)$ & $<0.0001$ \\
\hline Male (\%) & 44 & 58 & 30 & 60 & $<0.0001$ \\
\hline \multicolumn{6}{|l|}{ Comorbidity at entry } \\
\hline Diabetes $(\%)$ & 32 & 30 & 29 & 29 & 0.9613 \\
\hline Dyslipidemia (\%) & 57 & 67 & 68 & 65 & 0.2859 \\
\hline Obesity (\%) & 40 & 50 & 48 & 56 & 0.0655 \\
\hline Coronary artery disease $(\%)$ & 25 & 22 & 24 & 15 & 0.1762 \\
\hline Chronic heart failure (\%) & 32 & 16 & 26 & 9 & $<0.0001$ \\
\hline Stroke $(\%)$ & 42 & 28 & 37 & 17 & $<0.0001$ \\
\hline $\begin{array}{l}\text { Peripheral arterial } \\
\text { disease }(\%)\end{array}$ & 12 & 4 & 14 & 5 & 0.0031 \\
\hline Atrial fibrillation (\%) & 26 & 13 & 15 & 11 & 0.0033 \\
\hline Chronic kidney disease (\%) & 52 & 34 & 57 & 34 & 0.0002 \\
\hline \multicolumn{6}{|l|}{ Antihypertensive medications } \\
\hline ACE-I or ARB (\%) & 61 & 56 & 49 & 58 & 0.3464 \\
\hline Calcium channel blocker (\%) & 66 & 73 & 73 & 77 & 0.5952 \\
\hline
\end{tabular}

that compared to non-frail patients with systolic BP levels $<140 \mathrm{mmHg}$, frail patients with systolic BP levels $<140$ $\mathrm{mmHg}$ had highest risk of all-cause mortality, followed by systolic BP levels $\geq 140 \mathrm{mmHg}$. In non-frail patients, the risk of all-cause mortality was approximately 3.2 times higher in patients with systolic BP levels $\geq 140 \mathrm{mmHg}$ than in those with systolic BP levels $<140 \mathrm{mmHg}$, and the trend was similar even when subjects were restricted to those aged 75 years or older (Fig. 4).

\section{Background of aging and frailty}

Adults 75 years or over undergo many age-related physiologic and pathologic changes, such as BP regulation abnormalities and are likely to have complications such as frailty, cognitive dysfunction, and polypharmacy [20]. Therefore, therapeutic strategies for the elderly should be different from those for the young and middle-aged. Because older adults are a heterogeneous group, uniformly classifying them according to their age should be avoided. Frailty is considered a state of impaired homeostasis in response to stress and accelerated biologic aging [21]. One of the mechanisms contributing to the progression of frailty is inflammaging, a low-grade chronic inflammation associated with aging. Inflammatory cytokines activate muscle degradation to produce amino acids for energy or cleave antigenic peptides [22], which leads to hemodynamic instability. Studies evaluating the association between aging frailty and cardiovascular risk factors indicate that BP, lipids, and body weight levels are reduced in frail 
Table 2 Baseline anthropometric and laboratory findings of 535 patients in the Nambu Cohort Study stratified by baseline blood pressure and frailty status
Fig. 3 Adjusted hazard ratios and $95 \%$ confidence intervals for all-cause mortality for the combination of blood pressure and frailty status of 535 hypertensive patients in the Nambu Cohort Study

\begin{tabular}{|c|c|c|c|c|c|}
\hline & $<140 \mathrm{mmHg}$ & & $\geq 140 \mathrm{mmHg}$ & & \\
\hline & Frailty $n=114$ & $\begin{array}{l}\text { Non-frailty } \\
n=165\end{array}$ & Frailty $n=84$ & $\begin{array}{l}\text { Non-frailty } \\
n=172\end{array}$ & $p$ \\
\hline $\begin{array}{l}\text { Systolic blood } \\
\text { pressure }(\mathrm{mmHg})\end{array}$ & $126(118-134)$ & $129(120-135)$ & $152(145-160)$ & $150(143-158)$ & $<0.0001$ \\
\hline $\begin{array}{l}\text { Diastolic blood } \\
\text { pressure }(\mathrm{mmHg})\end{array}$ & $64(56-72)$ & $68(62-75)$ & $72(66-78)$ & $78(72-85)$ & $<0.0001$ \\
\hline Heart rate $(\mathrm{bpm})$ & $75(66-82)$ & $73(63-85)$ & $76(64-84)$ & $77(67-87)$ & 0.02171 \\
\hline Body mass index $\left(\mathrm{kg} / \mathrm{m}^{2}\right)$ & $\begin{array}{l}24.0 \\
(21.8-27.0)\end{array}$ & $\begin{array}{l}24.9 \\
(22.4-27.2)\end{array}$ & $\begin{array}{l}24.9 \\
(21.8-27.0)\end{array}$ & $\begin{array}{l}25.8 \\
(23.7-28.4)\end{array}$ & 0.0281 \\
\hline $\begin{array}{l}\text { Hand grip strength } \\
(\mathrm{kg}) \text { men }\end{array}$ & $\begin{array}{l}25.0 \\
(19.8-29.3)\end{array}$ & $29(24.6-34.0)$ & $\begin{array}{l}21.0 \\
(15.5-28.0)\end{array}$ & $\begin{array}{l}29.0 \\
(26.0-34.0)\end{array}$ & $<0.0001$ \\
\hline women & $\begin{array}{l}13.0 \\
(11.5-15.5)\end{array}$ & $\begin{array}{l}19.5 \\
(15.0-24.0)\end{array}$ & $\begin{array}{l}13.0 \\
(9.0-16.0)\end{array}$ & $\begin{array}{l}20.0 \\
(16.5-23.0)\end{array}$ & $<0.0001$ \\
\hline eGFR (ml/min/1.73 m²) & $59(46-71)$ & $65(55-75)$ & $55(42-67)$ & $67(55-80)$ & $<0.0001$ \\
\hline Uric acid (mg/dl) & $5.5(4.7-6.7)$ & $5.8(4.9-6.5)$ & $5.6(4.6-6.6)$ & $5.7(4.8-6.7)$ & 0.9152 \\
\hline $\begin{array}{l}\text { Fasting blood sugar } \\
(\mathrm{mg} / \mathrm{dl})\end{array}$ & $111(100-138)$ & $109(101-129)$ & $111(99-133)$ & $110(101-125)$ & 0.9349 \\
\hline HbA1c $(\%)$ & $5.8(5.5-6.1)$ & $5.9(5.7-6.2)$ & $5.8(5.5-6.2)$ & $5.9(5.6-6.2)$ & 0.3391 \\
\hline Total cholesterol (mg/dl) & $176(154-195)$ & $180(165-202)$ & $175(154-196)$ & $190(169-210)$ & 0.0001 \\
\hline HDL cholesterol (mg/dl) & $51(43-61)$ & $58(46-66)$ & $53(42-65)$ & $56(48-65)$ & 0.0317 \\
\hline Triglycerides (mg/dl) & $101(76-141)$ & $99(76-132)$ & $107(81-139)$ & $107(81-139)$ & 0.2624 \\
\hline LDL cholesterol (mg/dl) & $94(80-119)$ & $99(84-120)$ & $95(81-115)$ & $106(90-124)$ & 0.0151 \\
\hline White blood cell $\left(/ \mathrm{mm}^{3}\right)$ & $59(49-71)$ & $69(50-74)$ & $61(51-75)$ & $64(54-77)$ & 0.0983 \\
\hline Hemoglobin (g/dl) & $\begin{array}{l}12.3 \\
(10.9-13.9)\end{array}$ & $\begin{array}{l}13.1 \\
(12.5-14.2)\end{array}$ & $\begin{array}{l}12.2 \\
(11.3-13.4)\end{array}$ & $\begin{array}{l}13.5 \\
(12.6-14.5)\end{array}$ & $<0.0001$ \\
\hline Hematocrit (\%) & $38(34-42)$ & $40(38-43)$ & $38(35-41)$ & $42(39-44)$ & $<0.0001$ \\
\hline
\end{tabular}

$e G F R$ estimated glomerular filtration rate, $H D L$ high-density lipoprotein, $L D L$ low-density lipoprotein

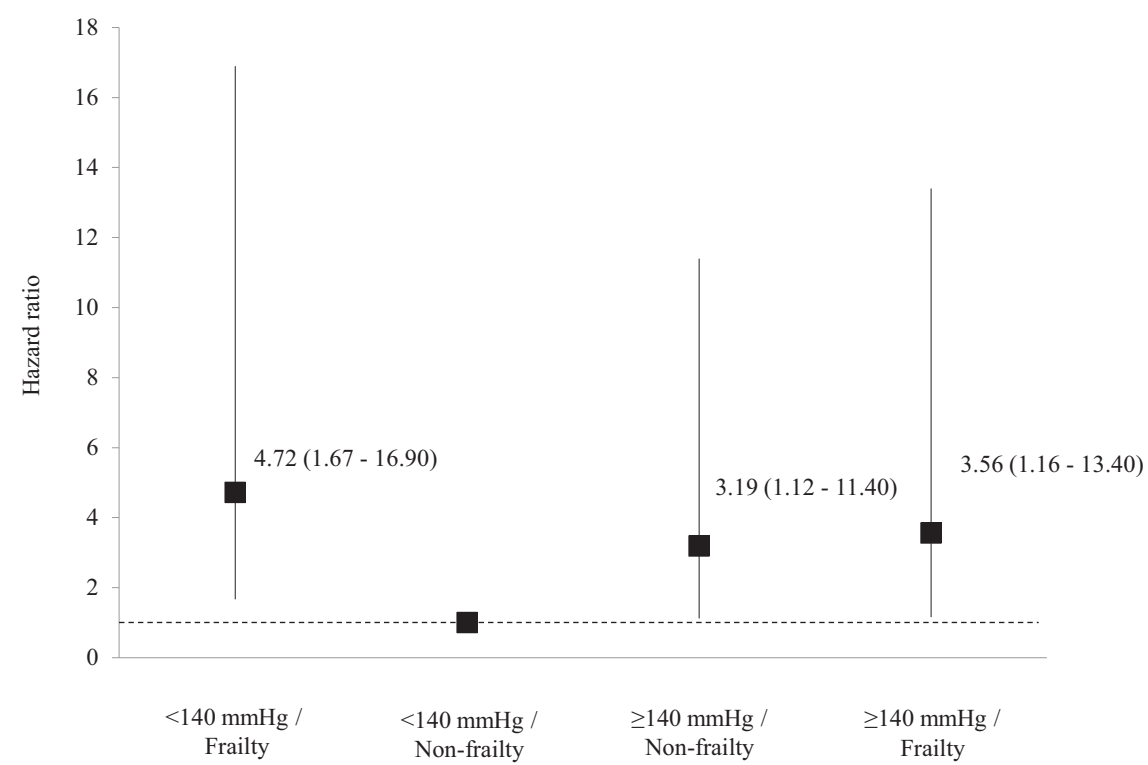

individuals, although comorbidities are more prevalent [1214]. Thus, in frail individuals, cardiovascular risk factors accumulate, while the level of each cardiovascular risk factor is somewhat reduced. In prescribing antihypertensive therapy for older patients, these characteristics of frailty should be kept in mind. 


\section{Interventional and epidemiologic studies of older hypertensive patients}

The results of a randomized controlled study on aggressive antihypertensive therapy targeting a systolic $\mathrm{BP}<140$ $\mathrm{mmHg}$ in patients aged 75 years or older showed that antihypertensive therapy targeting a systolic BP of $<140$ $\mathrm{mmHg}$ did not reduce the number of combined cerebrovascular events compared with therapy targeting a systolic $\mathrm{BP} \geq 140 \mathrm{mmHg}$, but did reduce all-cause and

Table 3 Number of deaths, mortality rates per 100 patients year and hazard ratios for all-cause death by blood pressure and frailty status of 535 hypertensive patients in the Nambu Cohort Study

\begin{tabular}{lll}
\hline & \multicolumn{2}{l}{ Systolic blood pressure level } \\
\cline { 2 - 3 } & $<140 \mathrm{mmHg}$ & $\geq 140 \mathrm{mmHg}$ \\
\hline Non-frailty & & 172 \\
$\mathrm{~N}$ & 165 & $76(68-81)$ \\
Median age & $75(69-80)$ & 13 \\
All-cause death & 4 & 2.36 \\
$\begin{array}{l}\text { Mortality rate }(/ 100 \\
\text { patients year) }\end{array}$ & 0.73 & $2.99(1.06-10.63)$ \\
Hazard ratios $(95 \%$ & & \\
confidence intervals $)^{\mathrm{a}}$ & $\mathrm{Reference}$ & \\
Frailty & & 84 \\
$\mathrm{~N}$ & 114 & $84(80-89)$ \\
$\begin{array}{l}\text { Median age } \\
\text { All-cause death }\end{array}$ & $82(75-87)$ & 14 \\
$\begin{array}{l}\text { Mortality rate }(/ 100 \\
\text { patients year) }\end{array}$ & 18 & 5.46 \\
Hazard ratios (95\% \\
confidence intervals)
\end{tabular}

${ }^{a}$ Adjusted for age and sex cerebrovascular disease mortality [23-28]. On the basis of these results, the JSH2019 set an antihypertensive therapy target for hypertensive patients aged 75 years or older at a systolic $\mathrm{BP}<140 \mathrm{mmHg}$ [9]. On the other hand, antihypertensive treatment of hypertensive patients with frailty has been discussed. Randomized controlled studies examining the antihypertensive treatment of frail patients include the HYpertension in the Very Elderly Trial (HYVET) [17] and the Systolic Blood Pressure Intervention Trial (SPRINT) [16], in which the authors concluded that there is no need to change the antihypertensive goal for patients with frailty. The interpretation of their results, however, has been questioned. First, although frailty is associated with lower levels of cardiovascular risk factors [12-14], the patients in both studies had higher levels of cardiovascular risk factors. Also, patients with comorbidities often found in frailty were excluded in these studies. Thus, many of the patients judged to be frail in the two studies could be classified as robust-prefrail by other criteria [29]. Furthermore, the BP values in SPRINT are not measured in a typical office setting. Extrapolation of results obtained in such a particular group of patients to the real world is not feasible.

In an epidemiologic study evaluating systolic BP and life expectancy in older hypertensive patients, low systolic BP levels increased total mortality [15]. In contrast, high systolic BP levels increased the risk of cardiovascular mortality, and there was a U-shaped association between systolic $\mathrm{BP}$ and the total mortality risk [30-32]. The optimal systolic BP level with the lowest risk of death was $130-150 \mathrm{mmHg}$ $[30,31]$, and the association between systolic BP level and life expectancy was similar in the older general population $[33,34]$. The association between systolic BP and frailty or dementia has also been reversed by background factors such

\begin{tabular}{|c|c|c|}
\hline \multirow{2}{*}{$\begin{array}{c}\text { Nambu Cohort Study } \\
\text { patients wit HTN }\end{array}$} & $\begin{array}{l}<140 \mathrm{mmHg} / \text { Frailty } \\
\end{array}$ \\
& $<140 \mathrm{mmHg} /$ Non-frailty \\
& $\geq 140 \mathrm{mmHg} /$ Frailty \\
& $\geq 140 \mathrm{mmHg} /$ Non-frailty \\
\hline
\end{tabular}

Hazard ratios $(95 \%$ CIs) for all-cause death for the combination of SBP and frailty

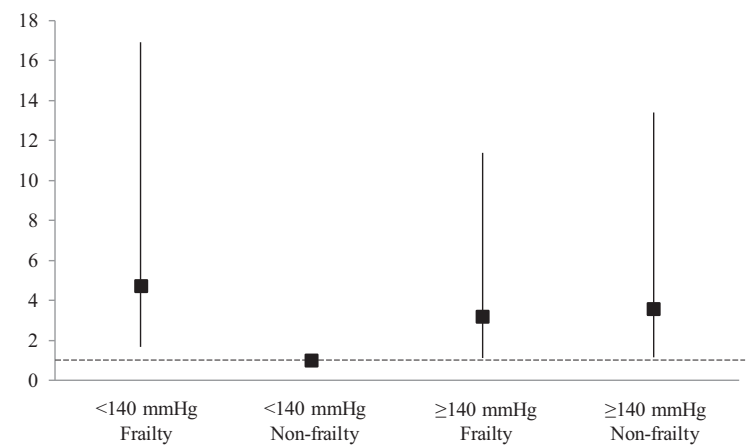

Fig. 4 Graphical Abstract: In elderly hypertensives, higher blood pressure levels are associated with an increased risk of death in non-frailty, while frailty has a greater mortality risk regardless of blood pressure levels 
as age, antihypertensive treatment, or comorbidities [35]. Therefore, the assessment of the association between BP levels and prognosis in older people should carefully be interpreted, taking into account a variety of factors.

The results of the present Nambu Cohort study, reconsidered in conjunction with existing evidence, led to the following findings. First, frail patients have lower BP levels. Second, frail patients have a higher risk of all-cause mortality regardless of BP level. Third, non-frail patients have a lower risk of all-cause mortality with lower BP levels. The absence of an interaction between systolic BP and frailty supports these results. The U-shaped relationship between systolic BP level and all-cause mortality shown in epidemiologic studies of older hypertensive patients can be explained by the combination of frailty and systolic BP levels.

\section{Future perspectives}

The JSH2019 set the antihypertensive therapy target for ambulatory hypertensive patients at $<140 / 90 \mathrm{mmHg}$, with frailty to be determined individually [9]. Randomized controlled trials in older patients, especially those evaluating frailty, are limited, and there are many challenges in generalizing their results. Individually assessed indications of potential benefits and harms of antihypertensive therapy rely mainly on the clinician's experience. Our results are consistent with the JSH2019 recommendations and suggest that an assessment of frailty has an essential role in determining the treatment strategy for older hypertensive patients. While antihypertensive therapy aimed at $<140$ $\mathrm{mmHg}$ may be effective in older non-frail patients, weaning a patient from frailty should be prioritized over therapy targeting BP levels in frail patients. Frailty may be an important marker to distinguish whether antihypertensive therapy aiming for systolic $\mathrm{BP}<140 \mathrm{mmHg}$ can reduce allcause mortality in older hypertensive patients.

\section{Limitation}

The present study has several limitations. First, the results of this study were derived from a prospective cohort analysis. Due to its observational nature, we may not have been able to rule out the effects of confounding factors, and the results show only an association and not causation. Second, the patients in this study were outpatients of a hospital or clinic, most of whom have multiple comorbidities. Therefore it is undeniable that discrepancies exist in the interpretation of the results with the general population or nursing home residents. Third, because $\beta$-blockers and diuretics are often administered for heart failure, only calcium channel blockers, angiotensin-converting enzyme inhibitors, and angiotensin receptor blockers were evaluated as antihypertensive agents. Fourth, BP values were evaluated using only the BP obtained at the initial office visit, but BP values during the follow-up were not considered. Lastly, the patients were residents of a relatively limited area-the southern part of Okinawa, Japan. Although the present analysis results were consistent with previous findings, these issues should be considered when interpreting the results of the present study.

\section{Conclusion}

The results of this prospective cohort study of ambulatory hypertensive patients indicated that frail patients had a higher risk of all-cause mortality than non-frail patients, regardless of BP level. In contrast, in non-frail patients, systolic BP $<140$ $\mathrm{mmHg}$ was associated with a lower risk of all-cause mortality. Frailty may be a useful marker for determining whether antihypertensive treatment is effective for reducing all-cause mortality in older hypertensive patients.

Acknowledgements The authors are grateful to Ms Makiko Chinen, Ms Masae Toma, Ms Mitsue Nakajo, Ms Asuka Kina, Ms Minako Kikuyama, Ms Megumi Ishiki, Ms Mizuki Ohkata, Ms Miwa Sunagawa, Ms Minako Yamaniha, Ms Masami Fukuyama, Ms Minatsu Yamashiro, Ms Megumi Kawabata, Ms Sawako Sakugawa, Ms Yuka Shimazaki, Ms Kaori Unten, Ms Mitsue Kuwae, Ms Shoko Nagamine, Ms Aya Henzan, Ms Sayuri Matsumura, Ms Yuko Kohno, Ms Yoko Karakasa, Ms Rie Kubota, and Dr Asuka Miiji for their dedicated work, and Mr Makoto Ohmine for retrieving the data. Furthermore, the authors would like to thank Prof Kunitoshi Iseki for his valuable advice regarding the preparation of this paper. Finally, the authors extend their sincere appreciation to $\mathrm{Mr}$ Kazuhide Nizato and $\mathrm{Ms}$ Kuniko Inoue for their dedicated assistance.

Author contributions TI, TS, MM, and HA designed the study. TI drafted the paper. TI and HA performed the statistical analysis. MT, KO, MK, TM, and OA coordinated the study. All authors read and approved the final paper.

\section{Compliance with ethical standards}

Conflict of interest The authors declare no competing interests.

Publisher's note Springer Nature remains neutral with regard to jurisdictional claims in published maps and institutional affiliations.

Open Access This article is licensed under a Creative Commons Attribution 4.0 International License, which permits use, sharing, adaptation, distribution and reproduction in any medium or format, as long as you give appropriate credit to the original author(s) and the source, provide a link to the Creative Commons license, and indicate if changes were made. The images or other third party material in this article are included in the article's Creative Commons license, unless indicated otherwise in a credit line to the material. If material is not included in the article's Creative Commons license and your intended use is not permitted by statutory regulation or exceeds the permitted use, you will need to obtain permission directly from the copyright holder. To view a copy of this license, visit http://creativecommons. org/licenses/by/4.0/. 


\section{References}

1. Fujiyoshi A, Ohkubo T, Miura K, Murakami Y, Nagasawa S-YY, Okamura $\mathrm{T}$, et al. Blood pressure categories and long-term risk of cardiovascular disease according to age group in Japanese men and women. Hypertens Res. 2012;35:947-53. https://doi.org/10. 1038/hr.2012.87

2. Arima H, Tanizaki Y, Yonemoto K, Doi Y, Ninomiya T, Hata J, et al. Impact of blood pressure levels on different types of stroke: the Hisayama study. J Hypertens. 2009;27:2437-43. https://doi. org/10.1097/HJH.0b013e328330e882

3. Ueshima H, Iimura O, Iida M, Okayama A, Sawai K, Minowa M. Impact of elevated blood pressure on mortality from all causes, cardiovascular diseases, heart disease and stroke among Japanese: 14 year follow-up of randomly selected population from Japanese - Nippon data 80. J Hum Hypertens. 2003;17:851-57. https://doi. org/10.1038/sj.jhh.1001602

4. Ettehad D, Emdin CA, Kiran A, Anderson SG, Callender T, Emberson $\mathrm{J}$, et al. Blood pressure lowering for prevention of cardiovascular disease and death: a systematic review and metaanalysis. Lancet (Lond, Engl). 2016;387:957-67. https://doi.org/ 10.1016/S0140-6736(15)01225-8

5. Thomopoulos C, Parati G, Zanchetti A. Effects of blood pressure lowering on outcome incidence in hypertension. 1. Overview, meta-analyses, and meta-regression analyses of randomized trials. J Hypertens. 2014;32:2285-95. https://doi.org/10.1097/HJH. 0000000000000378

6. Law MR, Morris JK, Wald NJ. Use of blood pressure lowering drugs in the prevention of cardiovascular disease: meta-analysis of 147 randomised trials in the context of expectations from prospective epidemiological studies. BMJ. 2009;338:b1665 https:// doi.org/10.1136/bmj.b1665

7. Lewington S, Clarke R, Qizilbash N, Peto R, Collins R. Agespecific relevance of usual blood pressure to vascular mortality: a meta-analysis of individual data for one million adults in 61 prospective studies. Lancet. 2002;360:1903-13. https://doi.org/10. 1016/s0140-6736(02)11911-8

8. Shimamoto K, Ando K, Fujita T, Hasebe N, Higaki J, Horiuchi M, et al. The Japanese Society of Hypertension Guidelines for the Management of Hypertension (JSH 2014). Hypertens Res. 2014;37:253-390. https://doi.org/10.1038/hr.2014.20

9. Umemura S, Arima H, Arima S, Asayama K, Dohi Y, Hirooka Y, et al. The Japanese Society of Hypertension Guidelines for the Management of Hypertension (JSH 2019). Hypertens Res. 2019;42:1235-481. https://doi.org/10.1038/s41440-019-0284-9

10. Xue Q-L. The frailty syndrome: definition and natural history. Clin Geriatr Med. 2011;27:1-15. https://doi.org/10.1016/j.cger. 2010.08.009

11. Rockwood K, Song X, MacKnight C, Bergman H, Hogan DB, McDowell I, et al. A global clinical measure of fitness and frailty in elderly people. CMAJ. 2005;173:489-95. https://doi.org/10. 1503/cmaj.050051

12. Ramsay SE, Arianayagam DS, Whincup PH, Lennon LT, Cryer J, Papacosta AO, et al. Cardiovascular risk profile and frailty in a population-based study of older British men. Heart. 2015;101:616-22. https://doi.org/10.1136/heartjnl-2014-306472

13. Matsuoka M, Inoue T, Shinjo T, Miiji A, Tamashiro M, Oba K, et al. Cardiovascular risk profile and frailty in Japanese outpatients: the Nambu Cohort Study. Hypertens Res. 2020;43:817-23. https://doi. org/10.1038/s41440-020-0427-z

14. Yanagita I, Fujihara Y, Eda T, Tajima M, Yonemura K, Kawajiri $\mathrm{T}$, et al. Low glycated hemoglobin level is associated with severity of frailty in Japanese elderly diabetes patients. J Diabetes Investig. 2018;9:419-25. https://doi.org/10.1111/jdi.12698
15. Rådholm K, Festin K, Falk M, Midlöv P, Mölstad S, Östgren CJ. Blood pressure and all-cause mortality: a prospective study of nursing home residents. Age Ageing. 2016;45:826-32. https://doi. org/10.1093/ageing/afw122

16. Williamson JD, Supiano MA, Applegate WB, Berlowitz DR, Campbell RC, Chertow GM, et al. Intensive vs Standard Blood Pressure Control and Cardiovascular Disease Outcomes in Adults Aged $\geq 75$ Years: a randomized clinical trial. JAMA. 2016;315:2673-82. https://doi.org/10.1001/jama.2016.7050

17. Warwick J, Falaschetti E, Rockwood K, Mitnitski A, Thijs L, Beckett $\mathrm{N}$, et al. No evidence that frailty modifies the positive impact of antihypertensive treatment in very elderly people: an investigation of the impact of frailty upon treatment effect in the HYpertension in the Very Elderly Trial (HYVET) study, a doubleblind, placeb. BMC Med. 2015;13:78 https://doi.org/10.1186/ s12916-015-0328-1

18. Arai H, Satake S. English translation of the Kihon Checklist. Geriatr Gerontol Int. 2015;15:518-9. https://doi.org/10.1111/ggi.12397

19. Satake S, Senda K, Hong Y-J, Miura H, Endo H, Sakurai T, et al. Validity of the Kihon Checklist for assessing frailty status. Geriatr Gerontol Int. 2016;16:709-15. https://doi.org/10.1111/ggi.12543

20. Benetos A. Hypertension: a Companion to Braunwald's Heart Disease - 3rd ed. In Philadelphia, PA: Elsevier; 2018. p. 396-404.

21. Ferrucci L, Cavazzini C, Corsi A, Bartali B, Russo CR, Lauretani $\mathrm{F}$, et al. Biomarkers of frailty in older persons. J Endocrinol Investig. J Endocrinol Invest 2002;25(10 Suppl):10-5.

22. Clegg A, Young J, Iliffe S, Rikkert MO, Rockwood K. Frailty in elderly people. Lancet (Lond, Engl). 2013;381:752-62. https:// doi.org/10.1016/S0140-6736(12)62167-9

23. Ninomiya T, Zoungas S, Neal B, Woodward M, Patel A, Perkovic $\mathrm{V}$, et al. Efficacy and safety of routine blood pressure lowering in older patients with diabetes: results from the ADVANCE trial. J Hypertens. 2010;28:1141-9.

24. JATOS Study Group. Principal results of the Japanese trial to assess optimal systolic blood pressure in elderly hypertensive patients (JATOS). Hypertens Res. 2008;31:2115-27. https://doi. org/10.1291/hypres.31.2115

25. Ogihara T, Saruta T, Rakugi H, Matsuoka H, Shimamoto K, Shimada $\mathrm{K}$, et al. Target blood pressure for treatment of isolated systolic hypertension in the elderly: valsartan in elderly isolated systolic hypertension study. Hypertens (Dallas, Tex 1979). 2010;56:196-202. https://doi.org/10.1161/HYPERTENSIONAHA. 109.146035

26. SPS3 Study Group, Benavente OR, Coffey CS, Conwit R, Hart RG, McClure LA, et al. Blood-pressure targets in patients with recent lacunar stroke: the SPS3 randomised trial. Lancet (London, England). 2013; 382: 507-15. https://doi.org/10.1016/S0140-6736(13)60852-1

27. SPRINT Research Group, Wright JT, Williamson JD, Whelton PK, Snyder JK, Sink KM, et al. A Randomized Trial of Intensive versus Standard Blood-Pressure Control. N Engl J Med. 2015; 373 : 151109120153006. https://doi.org/10.1056/NEJMoa1511939

28. Wei Y, Jin Z, Shen G, Zhao X, Yang W, Zhong Y, et al. Effects of Intensive Antihypertensive Treatment on Chinese Hypertensive Patients Older Than 70 Years. J Clin Hypertens. 2013;15:420-27. https://doi.org/10.1111/jch.12094

29. Rockwood K, Andrew M, Mitnitski A. A comparison of two approaches to measuring frailty in elderly people. J Gerontol - Ser A Biol Sci Med Sci. 2007;62:738-43. https://doi.org/10.1093/ gerona/62.7.738

30. Ravindrarajah R, Hazra NC, Hamada S, Charlton J, Jackson SHD, Dregan A, et al. Systolic Blood Pressure Trajectory, Frailty, and All-Cause Mortality $>80$ Years of Age: Cohort Study Using Electronic Health Records. Circulation. 2017;135:2357-68. https://doi.org/10.1161/CIRCULATIONAHA.116.026687 
31. Douros A, Tölle M, Ebert N, Gaedeke J, Huscher D, Kreutz R, et al. Control of blood pressure and risk of mortality in a cohort of older adults: the Berlin Initiative Study. Eur Heart J. 2019;40:2021-28. https://doi.org/10.1093/eurheartj/ehz071

32. Okumiya K, Matsubayashi K, Wada T, Fujisawa M, Osaki Y, Doi $\mathrm{Y}$, et al. A U-shaped association between home systolic blood pressure and four-year mortality in community-dwelling older men. J Am Geriatr Soc. 1999;47:1415-21. https://doi.org/10. 1111/j.1532-5415.1999.tb01559.x

33. Delgado J, Masoli JAH, Bowman K, Strain WD, Kuchel GA, Walters K, et al. Outcomes of Treated Hypertension at Age 80 and
Older: Cohort Analysis of 79,376 Individuals. J Am Geriatr Soc. 2017;65:995-1003. https://doi.org/10.1111/jgs.14712

34. Lv Y Bin, Gao X, Yin ZX, Chen HS, Luo JS, Brasher MS, et al. Revisiting the association of blood pressure with mortality in oldest old people in China: Community based, longitudinal prospective study. BMJ. 2018; 361. https://doi.org/10.1136/bmj.k2158

35. Kabayama M, Kamide K, Gondo Y, Masui Y, Nakagawa T, Ogawa $\mathrm{M}$, et al. The association of blood pressure with physical frailty and cognitive function in community-dwelling septuagenarians, octogenarians, and nonagenarians: the SONIC study. Hypertens Res. 2020;43:1421-29. https://doi.org/10.1038/S41440-020-0499-9 